\title{
Las voces limpio y poco en el habla sur Andina de Nariño, Colombia
}

\author{
The Words limpio and poco in the Andean Southern \\ Speech of the Department of Nariño, Colombia
}

As vozes limpio y poco na fala sul Andina de Nariño, Colômbia

Roberto Ramírez Bravo ${ }^{1}$

\section{Resumen}

Este trabajo examina la dimensión sociolingüística del uso de las voces limpio y poco en el habla sur andina nariñense; describe las singularidades fonéticas, morfosintácticas, léxico-semánticas y pragmáticas de las voces en cuestión, en diferentes contextos comunicativos; explica la convencionalidad de las mismas, en estructuras lingüísticas complejas y cotidianas. Para el logro de los propósitos, el estudio se apoya en la etnografía de la comunicación; en este sentido, la recolección de la información se lleva a efecto a través de la observación directa de conversaciones formales e informales y del diario de campo; se realizan grabaciones consentidas y anónimas en contextos de intercomunicación espontánea. Finalmente, se genera un conversatorio con los integrantes del Grupo de Investigación en Argumentación $(G I A),{ }^{2}$ con la intención de triangular los datos obtenidos y confrontar las estructuras sociolectales de los enunciados analizados.

\section{Palabras clave: Sociolingüística, limpio, poco, Nariño.}

\section{Abstract}

This paper examines the sociolinguistic dimension of the use of the words limpio and poco in the Andean southern speech of the Department of Nariño, Colombia; it describes the phonetic, morphosyntactic, lexical-semantic and pragmatic peculiarities of the aforementioned words in different communicative contexts; it explains their conventionality in complex and everyday linguistic structures. To achieve this purpose, the study relies on the ethnography of communication; in this regard, the recollection of information is carried out through direct observation of formal and informal conversations and of the field diary; consensual and anonymous recordings of spontaneous intercom contexts are performed. Finally, a discussion is generated with members of the Research Group in Argumentation- (RGA), with the purpose of triangulating data and confronting the sociolectal structures of the statements analyzed.

Keywords: Sociolinguistics, limpio, poco, Nariño.

\section{Resumo}

Este trabalho examina a dimensão sociolingüística do uso das vozes limpio y poco na fala sul andina nariñense; descreve as singularidades fonéticas, morfossintáticas, léxico-semânticas e pragmáticas, das vozes em questão em diferentes contextos comunicativos; explica a convencionalidade das mesmas, em estruturas lingüísticas complexas e cotidianas. Para o logro dos propósitos, o estudo apoia-se na etnografia da comunicação, neste sentido, a recoleção da informação se faz com efeito, a traves da observação direta de conversações formais e informais e do diário de campo; realizam-se gravações consentidas e anônimas em contextos de intercomunicação espontânea. Finalmente, se gera um diálogo com os integrantes do "Grupo de Investigación en Argumentación" (GIA), com a intensão de triangular os dados obtidos e confrontar as estruturas de dialeto social dos enunciados analisados.

Palavras-chave: Sociolingüistica, limpio, poco, Nariño.

Artículo recibido el 08 de abril de 2015 y aprobado el 26 de junio de 2015

1 Universidad de Nariño, Pasto, Colombia. Correo electrónico: renerene40@yahoo.es

2 Grupo de la Universidad de Nariño conformado por profesores de dicha Universidad y de algunas instituciones de Educación Básica y Media; por estudiantes de pregrado y de postgrado de la misma Universidad. Los integrantes, en su mayoría, son oriundos e hijos de padres oriundos de la zona sur Andina Nariñense. 


\section{Introducción}

El estudio sociolingüístico es un campo de reflexión multifacético; en este se escudriñan, especialmente, las peculiaridades lingüísticas del vocablo, del enunciado o del discurso producidos en contextos cotidianos de intercomunicación. En esta perspectiva, también se concibe la dimensión social e ideológica del enunciado, por cuanto el uso de determinado léxico, en estructuras lingüísticas específicas, muestra los imaginarios y los ideales de vida de los usuarios de la lengua.

Este documento aborda, fundamentalmente, la dimensión sociolingüística de las voces limpio y poco (en adelante entiéndase en los géneros masculino y femenino), utilizadas en la cotidianidad del habla sur andina nariñense; describe las singularidades fonéticas, morfosintácticas, léxico-semánticas y pragmáticas de dichas voces, en diferentes contextos comunicativos; explica la convencionalidad de las mismas, en enunciados espontáneos pero, a la vez, complejos. Estas voces se eligen por ser consideradas emblemáticas en la región, se establecen como formas representativas en diferentes contextos enunciativos y por distintos usuarios de la lengua, independientemente de la edad (más en los adultos que en los niños y adolescentes), del estrato o del rol que se desempeñe socialmente. Además, presentan curiosidades semánticas y pragmáticas, que en la cotidianidad pueden utilizarse, en algunos casos, como sinónimos y en otros como antónimos.

El estudio se apoya en la etnografía, dado que facilita y promueve la recolección de la información desde las realidades de interacción comunicativa, asumiendo los distintos componentes que integran la situación de habla, el evento y el acto de habla, para lo cual se recurre a la observación directa, al diario de campo y a grabaciones de conversaciones formales e informales. Se entiende por 'situación de habla' el escenario físico en el que se produce el enunciado; por 'evento', la necesidad de comunicar; y, por 'acto de habla', la ejecución del enunciado producto de la necesidad de intercomunicación.

El corpus de los datos recogidos es objeto de un conversatorio con los integrantes del Grupo de
Investigación en Argumentación (GIA), con el propósito de confrontar y precisar los usos de las voces objeto de estudio; se contrasta el tipo de usuario (común o eventual) de dichas formas, las situaciones, los eventos y los actos de habla en las que se utilizan. Este análisis colectivo admite distinguir y diferenciar la norma sociolectal y la excepcionalidad discursivas de la lengua estándar.

La investigación toma como referencia algunos elementos conceptuales básicos que interesan para comprender e interpretar el uso de una u otra lexía en el contexto discursivo de la comunidad de habla ya mencionada. En esta dirección, cabe destacar que, a lo largo de la historia, los estudios sociolingüísticos son objeto de trabajo apasionante por múltiples razones, entre ellas se alude a las siguientes:

a. Facilitan la detección de las formas a través de las cuales el usuario de la lengua organiza el pensamiento; revelan, de manera evidente o sugerente, los esquemas de representación que el sujeto posee sobre los fenómenos; $y$, proporcionan la comprensión de los sistemas simbólicos que le dan autenticidad al hablante.

b. Indican las elaboraciones y los órdenes lingüísticos establecidos para mencionar la realidad y explicarla en la complejidad de los detalles; expresan las formas a través de las cuales se ordena y se le da versatilidad al conocimiento.

c. Muestran las condiciones discursivas en las que el sujeto construye sociedad y se desenvuelve en ésta; explican la variedad de recursos expresivos que los integrantes del grupo social desarrolla para comprenderse mutuamente.

d. Exteriorizan el acervo lexicográfico y las formas lexicales de las que se sirve la comunidad para interactuar y configurar los grupos sociales; explicitan las estructuras lingüísticas recurrentes que tipifican o caracterizan 
las convenciones con las cuales se interpreta el mundo.

e. Revelan las representaciones lingüísticas, a través de las cuales se ejerce el poder, la manipulación, la discriminación, la exclusión, entre otros. Hacen viable el discernimiento sobre los discursos que promueven la inequidad y toda manifestación de violencia.

La investigación sociolingüística, resumida en las líneas anteriores, proporciona diversos niveles de estudio, los cuales proveen la profundización en el objeto de trabajo; alberga un amplio abanico de posibilidades investigadoras que se ahondan, principalmente, en los niveles de análisis lingüístico, como se leerá más adelante. En cada nivel lingüístico estudiado en este trabajo, se subsumen particularidades fonéticas, morfosintácticas, léxico-semánticas y pragmáticas representativas del valor de las palabras en contextos sociales de la comunidad de habla de la región sur andina nariñense, permitiendo descifrar y explicar la variación sociolectal, diferenciada de la lengua estándar.

\section{Metodología}

Como se dijo, este trabajo se apoya en la etnografía, por cuanto recurre a la comunidad de habla de la zona sur andina nariñense para analizar el objeto de estudio; asume la realidad lingüística dependiente de los sujetos informantes; se inspira en la hermenéutica para interpretar los sentidos ocultos de los enunciados; $y$, se interesa en comprender las prácticas comunicativas desde los sentires y los motivos de las interacciones de los actores (Hymes, 1971). Es decir, en esta investigación se interpreta los enunciados que incluyen las voces limpio y poco, desde contextos singulares y, desde los mismos, se reconoce la complejidad de lo sociocultural en lo lingüístico y lo sociolingüístico; se realiza un acercamiento a la etnografía de la comunicación, atendiendo a las reglas sociales y culturales, explícitas o no, que rigen el uso de las voces en cuestión, en un determinado contexto (Hymes, 1971).
Además, el análisis se establece en el marco de la etnografía ya que desagrega lo cultural en objetos más específicos, tales como la caracterización e interpretación de los términos objeto de estudio en pautas de socialización, en elementos que facilitan la construcción de valores semánticos, en expresiones que determinan competencias culturales y visiones de mundo, en la comprensión de reglas lingüísticas de interacción, entre otros. Se recoge la información a partir de la inmersión del investigador en el lugar, el espacio físico y el territorio donde surgen los acontecimientos, en este caso, sociolingüísticos; es decir, el investigador se sumerge en la cotidianidad del otro y, desde allí, sistematiza e interpreta los datos con los propios miembros de la comunidad de habla, para determinar la realidad y claridad discursivas (Tezanos, 2000).

Para la recolección de la información, se apela a la observación directa de situaciones de habla -conversaciones formales e informales o acto de habla propiamente dicho-; en un diario de campo se transcriben los distintos usos y modalidades de limpio y poco que se escuchan cotidianamente. Es necesario insistir en que la observación directa es determinante en el proceso investigador, se instaura en la fuente primaria para el levantamiento de los datos, los que se toman de los eventos y los actos de habla que se producen en situaciones reales y auténticas de acción discursiva, en los cuales, en su gran mayoría, participa el investigador como un actor más del acontecimiento comunicativo.

Por ser el investigador habitante oriundo de la zona, facilita la recolección del corpus (800 enunciados), el cual es permanentemente analizado y cribado de acuerdo con los propósitos de la investigación. Todos los enunciados se recogen en contextos reales de interacción comunicativa, en estos se realizan grabaciones consentidas y anónimas de los procesos de intercomunicación espontánea. Las grabaciones consentidas se llevan a efecto en conversaciones formales producidas en aulas de clase, oficinas, residencias, auditorios; y las informales se realizan en parques, canchas deportivas, parqueaderos, pasillos, zonas campestres; las grabaciones 
anónimas se realizan con discursos producidos en asambleas de juntas de acción comunal, juegos callejeros, plaza de mercado, supermercados, filas en bancos y en oficinas de servicios públicos, emisoras radiales rurales y en algunas entrevistas de la televisión local.

Una vez recogido el corpus, se efectúa un conversatorio con los integrantes del Grupo de Investigación en Argumentación (GIA), con el propósito de triangular la información (investigador, profesores y estudiantes que integran el grupo) y precisar la explicación del uso de las voces objeto de estudio. Con el corpus abierto al equipo, se analiza la fiabilidad del enunciado y especialmente los niveles de uso del mismo, es decir, la frecuencia y la población que utiliza el término o la estructura; además, se reflexiona sobre los distintos sentidos que puede adquirir el enunciado en diferentes contextos de acción comunicativa (el emisor, el receptor del mensaje, la forma, los propósitos, los resultados, el género, las formas de interpretación, entre otros aspectos). Algunos integrantes del grupo, por su condición de profesores de la zona rural del municipio de Pasto, aportan con los discursos que suelen producir los padres de familia y, en algunos casos, los estudiantes.

La muestra de informantes la conforman, en la gran mayoría, habitantes de la zona rural de estratos medio y bajo, con escolaridad básica y media, quienes se desempeñan como agricultores, amas de casa y en servicios varios; una minoría, la integran hablantes de la zona urbana de estratos medio y bajo, con escolaridad básica, media $y$, en proporción mínima, profesional, quienes se desempeñan en servicios varios, empleados, profesores de Educación Básica, Media y Educación Superior, excepcionalmente. Los informantes tienen edades por encima de los 25 años, oriundos de la región, con padres oriundos del municipio de Pasto, Ex Provincia de Obando (Túquerres, Ipiales, Guachucal, Cumbal), Tangua, Guaitarilla, Imues, Iles, Contadero, Gualmatan, Samaniego, Santacruz, Sandona, Yacuanquer, Consaca, especialmente. Es preciso señalar que la población infantil y adoles- cente utiliza con menor frecuencia las estructuras en cuestión, probablemente por la influencia de los medios de comunicación masiva y los procesos migratorios ocurridos por efectos del comercio y el desplazamiento forzado.

Con el fin de organizar el análisis del uso de los términos en cuestión, se toma como punto de referencia cada uno de los niveles de análisis lingüístico reseñados posteriormente, de manera sintética. En cada nivel de análisis se explicita el fenómeno, a través de ejemplos tomados de la realidad lingüística (situación de habla, evento y acto de habla) que ilustren al lector; el estudio se realiza con enunciados espontáneos que introducen el uso de cada término y se representan en contextos de interacción discursiva. La mayoría de los ejemplos transcritos forman parte de discursos amplios y contextualizados pero, por su extensión, se incluye únicamente, el fragmento que permite graficar la teoría.

Conviene señalar que, en algunos casos, se transcribe el enunciado que contiene la voz objeto de estudio y el enunciado alterno, que también se escucha, pero sin la inclusión de dicha voz. Para el análisis del nivel fonético de las voces se recurre a las grabaciones realizadas de manera anónima fundamentalmente, con lo cual se evita las hipercorrecciones $^{3}$ que se realizan en las grabaciones efectuadas de manera consentida.

\section{Análisis de la información}

En este apartado se describen y se explican los diferentes fenómenos que suscita la utilización de las voces limpio y poco en el habla sur andina de Nariño. Dichas voces se las somete a un examen en cada nivel de análisis lingüístico para especificar las particularidades fonéticas, morfosintácticas, léxico-semánticas y pragmáticas de las mismas, considerando la situación de habla, el evento y el acto de habla, es decir, el contexto de interacción comunicativa. Para graficar la situación de habla o el escenario físico se menciona al autor del enunciado,

3 La hipercorrección se entiende como el proceso de mejoramiento y adecuación consciente de la expresión, que tiene en cuenta la lengua estándar. 
identificándolo con la profesión que desempeña; este aspecto facilita deducir la intención y la necesidad de intercomunicación, por ejemplo, cuando el emisor es un agricultor, el enunciado se efectúa en el contexto del agricultor, cuando es un conductor, el enunciado se realiza en el escenario de la conducción y si el enunciado es de una ama de casa, el evento comunicativo se ejecuta, fundamentalmente en el contexto del hogar o de la residencia familiar.

\section{Fonética de las voces limpio y poco en el habla sur andina de Nariño}

La fonética describe y explica las distintas realizaciones de los fonemas en los procesos de intercomunicación; puntualiza la diversidad de alófonos que puede tener un fonema en la comunicación oral; visibiliza los rasgos sonoros de las estructuras lingüísticas expresadas por el hablante real en una situación comunicativa concreta; facilita la identificación de elementos suprasegmentales (tonales y acentuales) propios de un pueblo o de una comunidad de habla en particular. En este acápite se busca, a través de enunciados reales-auténticos, describir algunas características fonéticas de las voces nombradas con el propósito de precisar ciertos aspectos articulatorios y suprasegmentales que apoyan el valor semántico del término objeto de estudio.

Las principales realizaciones fonéticas ${ }^{4}$ de la voz limpio, que se encuentran en el habla sur andina nariñense son:

- Alargamiento y palatalización de la alveolar, fricativa, lateral, sonora $[1]<[1:] ;$ p. ej.: "[...] la tierra está [1:í:mpjo] seca [...]”5 (agricultor).

- Alargamiento vocálico de la vocal palatal, cerrada, anterior, alta, [i] < [í:]; el fenómeno se presenta a pesar de ser una vocal tónica en dicho contexto fónico; ej. "[...] los cuyes

4 Las transcripciones fonéticas de este trabajo se realizan en el contexto del Alfabeto Fonético Internacional (AFI).

5 El enunciado se produce a partir de la pregunta: “ ¿Cómo le fue en la cosecha don Max?" El señor Max responde: "Nos fue mal porque la tierra está limpio seca a causa del verano, el tiempo no nos ayudó esta vez y salimos jodidos". Por limitación de espacio no es posible transcribir la totalidad de cada uno de los discursos que contienen los enunciados tomados como ejemplo. están [l:í:mpjo] secos / los cuyes están excesivamente delgados - flacos_-" (ama de casa).

- Alveolarización del sonido bilabial, oclusivo sonoro, nasal $[\mathrm{m}]<[\grave{\eta} / \mathrm{m}]$; p. ej.: “[...] se casó con la Pepa y le fue [líi:njpjo] mal” (conductor de chiva).

- Desfonologización eventual del fonema bilabial, oclusivo, sordo [p] para producir una leve fricativización $[\beta]$ del mismo; $p$. ej.: "[...] el repollo está [l:í:m $\beta j o]$ podrido" (agricultor).

- Producción de la semiconsonante plena [j] en el diptongo creciente [jo]; ocurrencia de la yod [j], sonido palatal más cerrado que la vocal palatal [i]; p. ej.: “[...] la yerba está [1:í:mpjọ] mojada [...]” (agricultor).

- Breve cerramiento vocálico y tonificación (acentuación) del sonido velar, posterior, sonoro, medio $[\mathrm{o}]<[\hat{0}]$, tendencia a realizarse como [u]; p. ej.: “[...] me empape [l:í:mpjộ] / [l:í:mpju]” (albañil).

- Doble acentuación en la producción del seg-

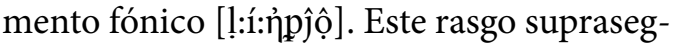
mental permite identificar los tonemas de cadencia [ $\uparrow]$ en el primer acento, y anticadencia en el segundo acento $[\downarrow]$; p. ej.: "El tablero está [l:í:mpị̣̂̂] manchado [...]" (profesor de Educación Básica).

- Finalmente, la transcripción fonética del vocablo, en la mayoría de los casos, puede ser [l:í:ท’pjộ̣] / [1:í:mpju]. Conviene señalar que los fenómenos descritos (doble acentuación, alargamiento y cerramiento vocálicos) son, entre otros aspectos, los que producen la curva melódica (el cantado) singular en el habla andina del nariñense.

Por su parte, las principales realizaciones fonéticas de la voz poco, que se encuentran en el habla sur andina nariñense, son:

- Producción plena de la bilabial, oclusiva, sorda [p]; se presenta esta realización en casos de hipercorrección [másbjén:póko] /más bien 
poco/, en cuyo caso la nasal que precede se produce de manera alargada; pero en el habla descuidada se pueden presentar casos excepcionales de desfonologización o relajamiento $y$ el fonema se realiza fricativizado $[\beta]$; de igual manera, cuando le precede un fonema nasal, en grupos fónicos tales como: [únßóko] / [másbjénßóko].

- Breve cerramiento vocálico y alargamiento del sonido interconsonántico velar, posterior, sonoro, medio: [o] < [ộ:]; p. ej.: “[...] al campo vienen [pộ:kó] / [pu:kó] los políticos [...]" (conductor de chiva).

- Producción plena del sonido velar, oclusivo, sordo [k]; p. ej.: “[...] siembran [pộ:kó] olluco [...]" (agricultor).

- Breve cerramiento vocálico del sonido velar, posterior, sonoro en posición final absoluta: [o] < [ộ]; p. ej.: “[...] estoy un [pókộ] / [pó:ku] enfermo" (carpintero citadino).

En síntesis, las voces en cuestión poseen características fonéticas compartidas en lo que respecta a la doble acentuación, al alargamiento y cerramiento vocálicos y a las asimilaciones (extensión de uno o de varios movimientos articulatorios) respectivas, producto de la cercanía fónica o de la contigüidad expresiva.

\section{Morfosintaxis de las voces limpio y poco en el habla sur andina de Nariño}

La morfosintaxis examina las formas de las estructuras lingüísticas en las dimensiones de la palabra y la oración. En la primera, indaga los morfemas (elementos significativos) que integran la estructura de la palabra y sus funciones, las derivaciones y las modificaciones a las que se ve avocada; en la segunda, analiza las variaciones $y$ funciones morfémicas que exige el contexto oracional, en atención a la estructura de los elementos lexicales anteriores o posteriores a los términos objetos de estudio.

En este nivel de análisis se describen y se explican las formas gramaticales, el empleo funcional y la combinación distribucional que adquieren las voces objeto de estudio. Se trata de visualizar la estructura formal de las palabras y la función que cumplen las mismas en la cadena oracional y discursiva. Para la explicación del caso, se recurre a estructuras lingüísticas del corpus levantado en conversaciones espontáneas y, en casos excepcionales, en conversaciones formales.

La palabra limpio, en la acepción estándar o con significación de limpieza, se estructura de la siguiente forma:

- Limpio-a-s: limpi = morfema léxico o lexema; $o / a=$ formantes constitutivos, morfemas de género masculino y femenino respectivamente; $s=$ formante constitutivo, morfema de número; p. ej.: "Manos limpias" (lema de la campaña de político).

- limpiecito -a: $\operatorname{limpi}=$ morfema léxico o lexema; $e c=$ formante facultativo o libre (interfijo); it = formante facultativo o libre, morfema de diminutivo; $\mathrm{o} / \mathrm{a}=$ morfemas de género masculino y femenino respectivamente, formantes constitutivos; p. ej.: “[...] el bus está limpiecito" (conductor de chiva).

También, la estructura con la acepción de aseado, se produce con la síncopa o elisión de los fonemas [e, c, i], cuando se trata de generar el diminutivo del término, así: limpito - $a$; se transcriben algunos discursos escuchados en la zona rural del municipio de Pasto, p. ej.: "[...] la ropa está limpita" / "la ropa está limpiecita"; "[...] debe ir bien limpito a la escuela" / "debe ir bien limpiecito a la escuela" (ama de casa); "[...] el carro quedo limpito" / "el carro quedó limpiecito” (profesora de Educación Básica).

En una o en otra forma, las estructuras limpio / limpia forman parte de un sinnúmero de enunciados, con funciones gramaticales de adverbio y de adjetivo, por ejemplo:

- Con función de adverbio de modo, significando muy: p. ej.: "[...] Rosalba estaba limpia / limpio chumada (amas de casa) / Rosalba estaba muy embriagada”; “Tu tarea está limpio mal” (profesora de Educación Básica) / "Tu 
tarea está muy mal". En uno y en otro caso, la voz limpio prescribe modificaciones al verbo "estar" (estaba y está), a su vez, a los adjetivos chumada y mal.

- Con función de adverbio de cantidad en estructuras elípticas y exclamativas, en las cuales la voz limpio cuantifica en grado extremo el fenómeno en cuestión; el caso se presenta en respuestas cortas a preguntas específicas, p. ej.:

Pregunta

Respuesta

- ¿Pedro está enfermo?

¡Limpio! (albañil) / ¡Muchísimo!

- ¿Le fue mal en la tarea? ------------

¡Limpio! (carpintero)/ ¡Bastante mal!

- ¿El cielo está oscuro?

¡Limpio! (agricultor) / ¡Excesivamente oscuro!

- De igual manera, se usa como adverbio de cantidad pospuesto al verbo, en estructuras tales como: "[...] se me entumieron limpio las piernas" / "se me entumieron bastante las piernas"; $y$ también pospuesto al sustantivo con idéntica función: "Se me entumieron las piernas limpio" (tendero) / "se me entumieron las piernas grado sumo". Estas formas son constantes en otros enunciados tales como: "[...] se me nublaron limpio los ojos" / "se me nublaron los ojos limpio" (cerrajero); “[...] se le arrugo limpio la cara" / "se le arrugo la cara limpio" (ama de casa); “[...] se le mocharon limpio las picas" / "se le mocharon las picas limpio" (agricultor).

- Con función de adjetivo (aumentando información al sustantivo), con la acepción semántica de pobre, p. ej.: "[...] estoy limpio" / "estoy sin dinero" (profesor de Educación Básica, zona rural); y como adjetivo predicativo, unido con el verbo copulativo "[...] Lucía está limpia, anoche la robaron" / "Lucía está sin dinero" (agricultor). En este último ejemplo, el vocablo puede sufrir modificaciones mor- fológicas y convertirse en verbo, con significado similar, tal es el caso: me limpiaron o la limpiaron / "me robaron o la robaron".

Para el caso de la voz poco se presentan los siguientes fenómenos morfosintácticos que merecen alguna consideración especial:

- Como adjetivo dicha voz expresa cantidad pequeña y se usa para el masculino poc-o "[...] en este instante tengo poco dinero $[\ldots]$ " (carpintero), y para el femenino poc- $a$, p. ej.: "[...] la vaca dio poca leche [...]" (ganadero).

- Como adverbio señala el grado de intensidad, p. ej.: “[...] los domingos se trabaja poco [...]" (tendero).

- Como sustantivo se le antepone el artículo, p. ej.: "Lo mucho se ve en lo poco". Para el diminutivo se escucha poqu-it-o-a o poquiti-co con la significación descrita.

Con lo señalado hasta ahora, se puede decir que dicha estructura se ajusta a la lengua estándar; el asunto se torna sociolectal cuando se producen derivaciones, tales como poquísimo/a, poquitísimo/a, poquisísimo/a, pocazo con significación de grandes cantidades, suficiencia y bastedad, p. ej.: "[...] junto un poquísimo de barro" (ama de casa) / "[...] sacó un poquitísimo de zanahoria” (obrero) / "[...] se le fue un poquisísimo de piedra” (albañil) / “[...] hay un pocazo de gusanos [...]" (agricultor).

La distribución morfémica, considerando el nivel sociolectal, se puede describir de la siguiente manera:

- $p o q u$-ís-im-o/a: poqu = morfema léxico o lexema; is = formante facultativo o libre, morfema de diminutivo en el que el fonema [s] sustituye al fonema $[t]$, de igual modo, hubo una síncopa del morfema it (poquitísimo), se presenta en la estructura que se describe más abajo; $i m$ = formante facultativo o libre (interfijo); $o-a=$ formantes constitutivos, morfemas de género masculino y femenino, respectivamente; puede presentarse escasamente el morfema $s$ = formante constitutivo, morfema de número. 
- $\quad$ oqu-it-ís-im-o/a: $p o q u=$ morfema léxico o lexema; it = formante facultativo o libre, morfema de diminutivo; is = formante facultativo o libre (interfijo); $i m=$ formante facultativo o libre (interfijo); $o-a=$ formantes constitutivos, morfemas de género masculino y femenino, respectivamente; puede presentarse escasamente el morfema $s$ como un formante constitutivo, morfema de número.

- $\quad$ oqu-is-ís-im-o/a: poqu = morfema léxico o lexema; is = formante facultativo o libre, morfema de diminutivo sustituto del morfema it; is = formante facultativo o libre (interfijo); $i m$ = formante facultativo o libre (interfijo); $o-a=$ formantes constitutivos, morfemas de género masculino y femenino, respectivamente; puede presentarse escasamente el morfema $s$ como un formante constitutivo, morfema de número.

- Poc-as-o/a: $p o c=$ morfema léxico o lexema; $a s=$ formante facultativo o libre, morfema de aumentativo; $o-a=$ formantes constitutivos, morfemas de género masculino y femenino, respectivamente; puede presentarse escasamente el morfema $s$ de número como un formante constitutivo.

Los términos referenciados funcionan como adjetivos y adverbios de cantidad con sentido ponderativo, de igual manera, se escuchan en estructuras expresivas cumpliendo función de sustantivo ponderativo con sentido contario al establecido en la lengua estándar, tal es el caso: "[...] en la plaza del carnaval hay un poco de gente [...]" (profesor universitario) / "en la Plaza del Carnaval hay mucha gente"; "[...] en la plaza del carnaval hay un poquísimo / poquisísimo de gente" (ama de casa) / "en la plaza del carnaval hay muchísima gente".

Otro ejemplo significativo, en el que se convierte en un adjetivo sustantivado y con características enfática y exclamativa ocasionales, es: "Qué poco de agua que tiene el mar" (obrero) / "Qué cantidad de agua que tiene el mar"; "Qué poquísimo de agua que tiene el mar" (conductor) / "Qué gran cantidad de agua que tiene el mar”. En estos ejemplos se destaca la doble posibilidad semántica que tienen las voces en cuestión, dado que se pueden entender como redundantes e innecesarios por la obviedad de la referencia o como elementos que eufemísticamente permiten enfatizar la enorme cantidad de agua: representan un modo de pensar y graficar la realidad. En uno o en otro sentido, el enunciado es afirmativo y se torna en una expresión sociolectal por la carga semántica que representa.

En estructuras tales como: "[...] las personas se echan pocazos de polvo [...]" (ama de casa) / las personas se lanzan bastante polvo"; "[...] regaste un pocazo de agua [...]" (ama de casa) / "regaste una gran cantidad de agua”, el término cumple función de sustantivo ponderativo. Es normal encontrar los términos poquísimo/a, poquitísimo/a, poquisísimo/a, pocazo, cumpliendo función de adjetivo; además, se los puede escuchar cumpliendo función de adverbios ponderativos en "[...] comió poquísimo y se fue [...]" / "comió poquitísimo y se fue" / "comió poquisísimo y se fue" (amas de casa), con el significado de mínima cantidad, en todos los casos.

Independientemente de la escolaridad, del estrato social, de la procedencia, del sexo, es común escuchar, con la función de adverbio, la estructura "más bien poco", para referir cantidad mínima. Lo interesante es que dicha expresión se utiliza como el cliché para responder a una variedad de preguntas, por ejemplo:

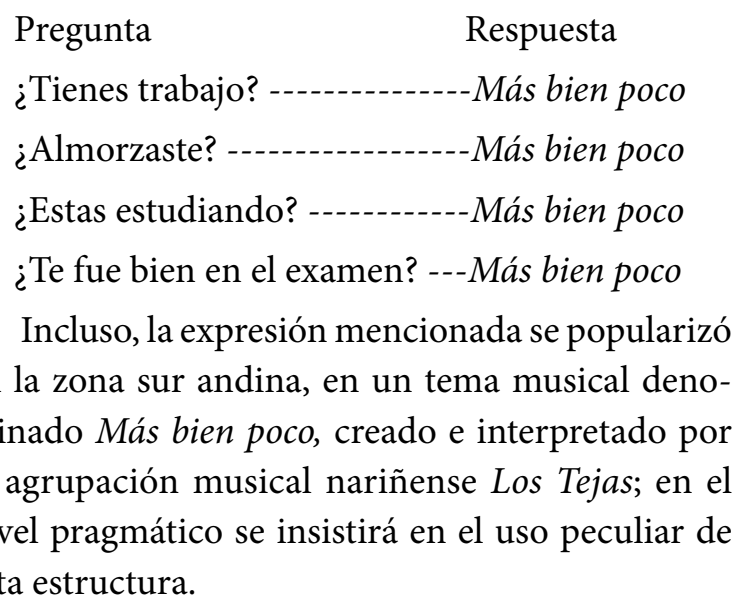




\section{Léxico-semántica de las voces limpio y poco en el habla sur andina de Nariño}

La lexicografía se ocupa de indagar en la lengua las diferentes entradas léxicas con sus respectivas acepciones, con el fin de elaborar diccionarios o glosarios. En el presente trabajo no se trata de elaborar ninguno de los dos documentos enunciados; se busca indagar las particularidades léxico-semánticas que los términos en cuestión adquieren en las construcciones sintácticas que realiza el habitante de la zona sur andina nariñense. La semántica escudriña las distintas acepciones significativas que adquieren las entradas léxicas; revisa la evolución de los significados de la estructura, en enlace con los referentes que designa y considerando la norma lingüística; en el caso que nos ocupa, reivindica y explica los alcances de la sinonimia y la antonimia de los términos limpio y poco, en el contexto discursivo.

En este apartado se examina cuidadosamente las diferentes características léxico-semánticas que adquieren los términos limpio / limpia, poco / poca en algunos diccionarios y glosarios de mayor representatividad en el contexto regional e internacional. Dicho de otra manera, se explicita la valoración significativa que se les da a los términos en cuestión en el contexto elegido.

En el rastreo de algunos diccionarios y glosarios elaborados con la terminología de uso específico en el contexto nariñense, aparece la estructura limpio como "ponderativo" (Pazos, 1972, p. 23) y limpio sucio / definido como "totalmente sucio" (Álvarez, 1984, p. 53; Bolaños, 1975, p. 46) y se las identifica como particularidades léxicas de la región. Probablemente, los autores encuentran la singularidad del término en la contradicción que suscita la palabra limpio- $a$ junto a la voz sucio- $a$, en contextos específicos de interacción comunicativa.

En el diccionario inga ${ }^{6}$ (Tandioy, Levinson y Maffla, 1978, p. 132) se encuentra la estructura lim / limpu / utilizados en Santiago, Putumayo; y limpi / lin utilizado en San Andrés del Putumayo como

6 Lengua aborigen perteneciente a la familia de la lengua quechua; la misma se habla en el alto Putumayo, Colombia, por la comunidad inga. adverbio que significa "completamente". Además, incluye un ejemplo en lengua inga, a saber: Asuami carancuna, lin machangapa (le dieron chicha para emborracharlo completamente). En el mencionado diccionario, también se registra la palabra tipcarisca como participio pasado, "pelado, limpio" (p. 273) y la palabra española limpio, se la traduce como tipcarisca (p. 364). Según las anteriores estructuras, especialmente limpi / lin, con su respectiva acepción -completamente-, es dable plantear, hipotéticamente, que el sentido que se le proporciona al término limpio (con el sentido de "muy") resulta de una fusión lingüística entre el español y el inga.

Según el Diccionario de la Real Academia (DRAE), dichas voces se definen de la siguiente manera: limpio (adjetivo del latín limpîdus) "que no tiene mancha o suciedad. Que no tiene mezcla de otra cosa [...]. Despojado de lo superfluo, accesorio o inútil”. Entre algunas de las acepciones especificadas por Moliner (1998), tenemos las siguientes: "sin confusión o embarullamiento" y entre los ejemplos destacamos: "cuentas limpias, a grito limpio, a puño limpio, conciencia limpia, limpio de corazón”, entre otros. Además, agrega la estructura limpia con la acepción de disminución o supresión, en el caso de: "han hecho una limpia en el personal".

Probablemente, la última acepción tiene correspondencia con la utilizada en la zona sur andina, con la referencia de despojo o de robo, por ejemplo: "[...] la mujer me dejó limpio [...]" (carpintero) / "mi esposa me quitó todo el dinero"; "[...] anoche me limpiaron en el centro [...]" (cerrajero) / "anoche me robaron todo el dinero". De igual manera se escucha: "[...] ando limpio vaciado / [...] siempre estás limpio, no gastas nada [...] / [...] la vieja me limpió [...]" con la acepción de: "Estar sin dinero" (enunciados producidos por vendedores de frutas, grabados en el bus urbano en la ciudad de Pasto).

Sobre el adverbio poco / poca no hay registro especial en los diccionarios y glosarios elaborados con voces del habla andina nariñense. El diccionario inga lo traduce como tinlla que significa "casi ocurre lo contrario"; de igual forma se utiliza lo voz maylla, adjetivo que traduce "un poco", ejemplos: máyllallapas 
caray (¡dele algo! Aunque sea poco); maylla suma / aslla suma iqué hermoso!; aslla adverbio que traduce "poco", asllita "un poquito, medio".

El Diccionario ilustrado Vox latino-español / espanol-latino (1992) señala paucitas-atis como "poquedad, escasez" y paucus-a-um como "poco, escaso, corto en número". El DRAE especifica la evolución del término latino paucus, lo clasifica como un adjetivo manifiesto en poco / poca, con la definición de escaso, limitado y corto en cantidad y calidad. Lo asume como adverbio "canta poco"; como locución adverbial "por poco / a poco / en poco / poco a poco / poco más o menos / un poco"; como locución adjetival "de poco / para poco", en todos los casos con la significación de disminución. Por su parte, Moliner (1998) precisa el uso de poco- $a$ como adjetivo cuando "expresa cantidad pequeña o número pequeño de la cosa expresada por el nombre y es variable: poco dinero [...]. Como adverbio expresa poca intensidad o grado y es invariable: "hemos adelantado poco". Cabe advertir que la autora hace un amplio análisis de las diferentes estructuras y funciones gramaticales en las que se inserta la voz poco y, en todas ellas, la significación es equivalente a disminución en cantidad o calidad del fenómeno nombrado.

La curiosidad lingüística y sociolectal que representa el uso del adjetivo limpio radica en su valor semántico. Como ya se dijo, dicha voz genera estructuras, tales como: "limpio sucio" en la que el adjetivo limpio se utiliza como un sustituto del adverbio muy. Y, resulta interesante la aparente contradicción pero, en atención a la estructura gramatical y al sentido del enunciado, de lo que se trata es de enfatizar el valor de la voz sucio. Además, es posible señalar que dicho elemento léxico se conciba como forma de admiración, en virtud del desconcierto que suscita en el hablante el fenómeno que trata de referir y de describir.

Otras estructuras, a saber: "limpio corrompido / muy corrupto"; "limpio chumado / muy borracho o totalmente ebrio"; "limpio oscuro / muy oscuro"; "limpio dormido / muy dormido"; "limpio acabado / viejo" sugieren sentidos extremos, totales y deci- sivos. Así las cosas, la semántica de la voz limpio se establece, seguramente, como una condición de perfectibilidad del fenómeno; fácilmente se deduce que, en los acontecimientos descritos, el fenómeno se generó por completo (enunciados producidos por amas de casa y grabados anónimamente en el parque de la ciudad de Túquerres, son extraídos de discursos más amplios).

Para el caso de la voz poco, en enunciados tales como: "[...] Qué poco de agua que tiene el mar [...]" (obrero) / "Qué cantidad de agua que tiene el mar"; "[...]Qué poquísimo de agua que tiene el mar [...]" (conductor de bus) / "Qué gran cantidad de agua que tiene el mar", las posibilidades interpretativas son diversas, dado que, como ya se dijo, la voz adquiere, por una parte, un valor ampuloso y, por otra, un valor superfluo por la obviedad de la referencia; de igual manera, la voz puede ser utilizada como ironía que permite enfatizar la enorme cantidad de agua: adquiere simultáneamente el significado antónimo.

Conviene aclarar que en el habla andina nariñense, al igual que en distintas regiones de habla hispana, las cantidades designadas con poco, poquito $y$ poquitico son diferentes, de tal manera que a la última voz le corresponde menor cantidad que a la anterior $\mathrm{y}$, a esta, menor cantidad que a la primera. Por ejemplo: "la cosecha fue poca" refiere una cantidad mayor a "la cosecha fue poquita", y esta refiere mayor cantidad que "la cosecha fue poquitica"; es decir, en el último caso representa mínima cantidad frente al primero.

Cabe decir que la voz limpio se define de manera más o menos similar en los distintos diccionarios y glosarios consultados a excepción del diccionario inga; semánticamente, el término es polisémico y sugiere diversas interpretaciones. La voz poco no es tratada como un término específico del contexto andino y, en los diccionarios de uso generalizado de la lengua española, como se advierte, el concepto es estándar; no obstante, en el contexto descrito resulta ser una curiosidad semántica sociolectal interesante por las singularidades de sentido que admite. El DRAE y el Diccionario de uso del español de Moliner (1998) precisan las diferentes funciones gramaticales 
que desempeñan dichas voces, según la aplicación que tengan en la estructura oracional.

Resulta original la utilidad sinonímica que se les da a las voces en cuestión en estructuras, tales como: "[...] tienes un poco de polvo en la cabeza [...]" (artesano del carnaval) / "[...] estas limpio polvo la cabeza [...]" (artesano del carnaval) / "tienes bastante polvo en la cabeza"; o los enunciados: "[...] el agua está limpio sucia [...]" / "El agua tiene un poco de mugre" (amas de casa), lo que significa que el agua es imposible consumirse. De igual modo, se encuentran giros semánticos en los que la utilidad de los dos términos se aproximan a la antonimia, p. ej.: “[...] Rosalba llegó limpio tarde a la reunión [...]" / "[...] Luis llegó poco tarde a la reunión [...]" (secretario Junta de Acción Comunal) cuya diferencia estriba en que Rosalba llegó excesivamente tarde y Luis llegó casi puntual; “[...] los niños están limpio enfermos" / “[...] las niñas, más bien están poco enfermas" (amas de casa), lo que significa, en el primer caso, la enfermedad absoluta y, en el segundo caso, aproximadamente, la ausencia de enfermedad.

En uno y en otro enunciado, como se describe posteriormente, el hablante, indiscutiblemente, recurre a los contextos de intercomunicación para definir con mayor claridad el sentido del término; es la circunstancia del proceso de intercomunicación; son la situación de habla, el evento y el acto de habla los que definen la polisemia, la sinonimia o la antonimia de las voces y, fundamentalmente, la habilidad del hablante para discernir y definir el sentido que desea transmitir el enunciador.

\section{Pragmática de las voces limpio y poco en el habla andina de Nariño}

La pragmática averigua el valor de uso que adquieren los términos en contextos particulares de intercomunicación; en conjunción con la semántica, revisa la significancia $y$, en ella, los sentidos que adquieren las palabras en actos de habla o en conversaciones reales; visibiliza la carga ideológica que se subsume en la elaboración de los enunciados, es decir, facilita las herramientas para dirimir los ima- ginarios y los ideales de vida manifiestos o sugeridos en las palabras.

En este apartado se describe, en contextos discursivos, los diferentes usos de las voces en cuestión; se señalan particularidades estilísticas e ideológicas que subyacen en la producción de los términos. Una vez más, es necesario aclarar que estas formas lexicales paulatinamente están desapareciendo por la influencia de la migración (producto del desplazamiento y de propósitos comerciales) de pobladores de las zonas norte y oriental colombianas; no obstante, en las zonas rurales, especialmente del sur nariñense, son visibles y representativas.

En las estructuras "[...] limpio sucio [...]" (carpintero), "[...] limpio mal [...]" (cerrajero), “[...] limpio viringa [...]" (ama de casa), “[...] limpio muerto [...]" (vendedor ambulante), "[...] limpio embarrado [...]" (agricultor), "[...] limpio mojado [...]" (albañil), “[...] limpio frio [...] " (tendero), "[...] limpio caliente [...]" (obrero), “[...] limpio tarde [...]” (profesor de Educación Básica) ${ }^{7}$, gramaticalmente se produce la sustitución del adverbio muy; pero desde el punto de vista del estilo se sospecha sobre otra forma de ver las situaciones o los fenómenos: para una hablante de la región no representan lo mismo los enunciados muy mal y limpio mal, en el primer caso supone que "algo está mal o extremadamente mal"; en el segundo caso presume que "algo está terriblemente mal", que excluye cualquier posibilidad de que el hecho o el fenómeno tuviere algo bueno.

En las estructuras “ $[. .$.$] se me entumieron limpio$ las piernas" / "[...] se me entumieron las piernas limpio [...]" (tendero), el uso de limpio no es fácilmente sustituido por "se me entumieron mucho / bastante las piernas". En las primeras estructuras, la ponderación sobrecoge al oyente, e incluso, lo pone alerta con la situación que se puede estar presentando, probablemente es necesario avizorar detenidamente la circunstancia; en la descripción fonética de la voz se puede identificar el énfasis en la curva melódica

7 Enunciados grabados en los sitios que sugieren las profesiones; de igual modo, se escuchan en parques, parqueaderos y campos deportivos de Ipiales y Pasto. 
(conjuntamente con los tonemas de cadencia, suspensión y de anticadencia), que sugiere cierta desesperación [^l:í: $\rightarrow$ mpjộộ]. En el segundo caso, el enunciado inquieta pero no desespera, el oyente lo asume como la realidad cotidiana que suele presentarse en distintos ambientes de acción.

La voz limpio, como se dijo, puede ser el fruto del sincretismo lingüístico entre el término inga limpi y el término español limpio; pero también se puede constituir en un acomodamiento lingüístico de limpi, lo que quiere decir que es una voz que proviene de la lengua inga y se ajusta a la estructura lingüística del español. Considerando esta última opción, el significado de limpio es completamente y los sentidos que se le dé en las distintas estructuras están en consonancia con éste: totalmente, plenamente, integramente, indiscutiblemente, absolutamente, radicalmente, definitivamente, tajantemente, etc.

Dado que la voz en cuestión es recurrente en diversas conversaciones y en distintos enunciados, por distintos usuarios de la lengua, en una región específica no es aventurado sugerir que la misma representa la forma de ser y de estar en el mundo; es decir, forma parte del capital simbólico y refleja la visión o la ideología del hablante sobre su condición; implica la referencia total de los actos y de los pensamientos, desde la cual se toman determinadas decisiones. Las realidades vistas o caracterizadas como totalidades sugieren integralidad y requieren de escisiones para ser comprendidas en su verdadera dimensión.

En las estructuras "poco de gente", "poquísimo de gente", "poconón de gente" "pocazo de polvo", "poco de agua”, si bien en la lengua estándar el término poco se define como escaso, insuficiente, exiguo, parco, pequeño, irrisorio, etcétera; en el contexto de la zona andina nariñense, especialmente sureña, se presume de mucho, abundante, nutrido, multitudinario, excesivo, numeroso, incontable, cuantioso, desmedido, profuso, inconmensurable, extenso. Pero también, el término se usa para significar lo establecido en la lengua estándar, es decir, es sorprendente como los hablantes de la zona logran asumirlo como antónimo, diferenciando un sentido de otro, atendiendo a los contextos de intercomunicación.

Enunciados tales como: "[...] hubo poca gente en la iglesia [...]" (sacerdote), "[...] pocos parientes estuvieron en mi grado" (profesor universitario), "[...] a la reunión de padres de familia fueron pocos" (profesor de Educación Básica), "[...] la reunión duro poco [...]" (presidente de Junta de Acción comunal), la voz poco designa escasa cantidad de personas o de tiempo; no obstante, los hablantes, dependiendo de la circunstancia, suelen producir los siguiente giros gramaticales: "[...] hubo un poco de gente en la iglesia [...]" (sacerdote, sacristán); "[...] un poco de parientes estuvieron en mi grado" (profesional universitario), dicha voz adquiere la significancia de abundante. La entonación enfática y la marcación del término con el artículo indefinido un facilita delimitar el significado pragmático del mismo en los enunciados descritos; sin embargo, en enunciados, tales como: "[...] téngame un poco de paciencia” (profesor universitario); “[...] tráigame un poco de maíz [...]” (agricultor terminando la siembra); “[...] lleve un poco de yerba [...]" (agricultor en plaza de mercado) no procede igual, en este caso se entiende como cantidad mínima.

Con base en la descripción de los ejemplos citados, se deduce que la voz poco tiene la doble acepción: se utiliza en el sentido estandarizado escaso-y con su antónimo - abundante- Es preciso señalar que la voz poco es recurrente en diversas conversaciones y en distintos enunciados y sugiere concepciones impredecibles y complejas de la realidad. Como se mencionó, en algunas situaciones de habla, dicha voz referencia insuficiencia, y en otras, abundancia; en unas sugiere fracciones, y en otras, totalidades.

La estructura popularizada "más bien poco", relacionada anteriormente, es recurrente en distintas conversaciones en la zona rural y urbana, utilizada por hablantes con bajos o altos niveles de escolaridad, independientemente del estrato social. Se constituye en el cliché que referencia el estado de ánimo más que la cantidad o la magnitud del fenómeno; es una manera de representar cierta condición de 
desidia frente al hecho ocurrido. La estructura puede ser una respuesta a una pregunta o el complemento a una aseveración, por ejemplo, en el primer caso: ¿Tienes hambre? < "Más bien poco"; ¿la cosecha está buena? < "Más bien poco"; en el segundo caso: Usted tiene buena mano para la siembra < "Más bien poco"; la vecina lo estima mucho < "Más bien poco", se puede entender como: "No es tanto como se cree / las apariencias engañan" o "mejor es poco / no me halaga”, una u otra acepción la determina el contexto de interacción comunicativa.

Suelen presentarse conversaciones excepcionales en las que algunos hablantes usan simultáneamente las voces limpio y poco; son enunciados singulares que el escucha desprevenido puede tener dificultades en la comprensión, por ejemplo: "[...] el balde está poco limpio [...]" / "el balde está sucio"; “[...] la marranera está poco limpia [...]" / "La marranera está sucia"; [...] el patio está poco limpio [...]" / "El patio está sucio". En estos casos, tanto poco como limpio adquieren el significado estándar de escaso / insuficiente y aseado / pulcro respectivamente. Se aclara que la voz poco en los enunciados señalados funciona como un atenuante de la situación; es un paliativo a la categoría sucio / indecoroso lo que supone, depende de la entonación del hablante, la necesidad de cambiar la situación o la sugerencia de dejarla como está.

En otras palabras, el uso de limpio y poco, más en la zona rural que en la zona urbana, son otras afinidades lingüísticas sociolectales de la región que representan las características complejas del habla sur andina nariñense. En términos de Wittgenstein (1958/1988, 1969/2000), son juegos verbales que grafican la dinámica y la versatilidad del lenguaje; se constituyen en elementos sociolingüísticos que proporcionan identidad referencial. Reflejan elementos auténticos de las formas de ver y de pensar el lugar y el mundo que construye y habita el hablante en cuestión; dicho en otras palabras, sobrepasan el nivel de la pragmática a unas dimensiones sociosemánticas o sociosemióticas complejas.

\section{Conclusiones}

Las investigaciones que se han realizado en el tema del habla andina nariñense son diversas, asumen diferentes tópicos que describen y, en algunos casos, explican las peculiaridades del habla en cuestión. El trabajo Observaciones sobre el habla de la zona andina nariñense, desarrollado por Maffla, Ramírez y Bastidas (2012) muestra, a grandes rasgos, varias indagaciones adelantadas al respecto, en los niveles fonético-fonológico, morfosintáctico, lexicográfico, semántico y pragmático. Principalmente, es un bosquejo del estado del arte de la investigación lingüística desarrollada sobre el habla de la región nariñense.

De manera particular, los trabajos de Álvarez (1984), Pazos (1972), Bolaños (1975), Sanz (2006), entre otros, elaboran glosarios, en algunos casos los llaman diccionarios, en los cuales registran un buen número de palabras, con su respectivo significado, utilizadas en la región nariñense. Por su parte, Arbor (1975), Pabón (1988), Maffla (2006), Ramírez (1994, 1996), Cisneros (2001), entre otros, trabajan aspectos fonéticos en unos casos y morfosintácticos y semánticos en otros. Cada uno de los autores resalta un aspecto particular del habla andina nariñense; sin embargo, no puntualizan el tema tratado en este documento.

Habitualmente, los autores mencionados asumen tópicos amplios que señalan características generales y específicas en las dimensiones lexicográfica, fonética, morfosintáctica y semántica del habla nariñense. Estos documentos propician y apoyan la investigación en algunos aspectos puntuales como los tratados en este escrito; son pretextos y ayudas bibliográficas que permiten fundamentar estudios particulares necesarios para comprender e interpretar, de manera más cercana, el pensamiento del hablante andino nariñense.

Este documento se constituye en una proyección de las investigaciones desarrolladas por los autores mencionados, se puede decir que es complementario en algunos aspectos e innovador en otros: complementario porque reafirma características definidas de la comunidad de habla, insistiendo en lo 
sociolectal de la doble acentuación, en el uso de los diminutivos, además de otros aspectos; innovador porque permite dilucidar la aparente contradicción semántica establecida por el hablante desprevenido. Entre las conclusiones que resaltan se mencionan las siguientes:

Las voces limpio y poco, en general, se realizan fonéticamente con los rasgos distintivos del hablante nariñense andino: cerramiento vocálico, doble acentuación y alargamientos vocálicos, elementos fundamentales que producen la curva melódica (el cantado) particular en el hablante de la región. Morfosintácticamente, los términos en cuestión se utilizan en función de adjetivos, adverbios y, en algunos casos, en función de sustantivos. En diversos casos, la voz limpio se puede escuchar como una expresión admirativa y la voz poco en momentos excepcionales.

Desde el punto de vista léxico-semántico, es probable que la voz limpio sea un sincretismo de la voz inga limpi con la voz hispana limpio. Este fenómeno trae consigo las acepciones semánticas con el sentido de total, absoluto, radical, definitivo, etc., $y$, en algunas estructuras sincréticas, las aparentes contradicciones semánticas entre sí (limpio sucio).

En el caso de la voz poco, posiblemente se haga la extensión semántica de la forma admirativa del inga maylla suma / aslla suma = poco ¡qué hermoso / qué grandioso!, de tal manera que por acomodamiento semántico, evoluciona a suficiente, abundante y se utilice como tal, lo que genera la acepción antónima.

En la perspectiva pragmática, las voces comentadas, con la acepción sociolectal, es decir, para enfatizar el acontecimiento o la circunstancia que refieren, se utilizan regularmente en conversaciones formales y consecutivamente en conversaciones informales, por el hablante de la zona rural, con escolaridad básica y con estrato social bajo. Con la acepción estandarizada, es utilizada, especialmente, por el hablante urbano, con escolaridad profesional y con estrato social medio y alto, en conversaciones formales; y la acepción sociolectal la utilizan escasamente, en conversaciones informales y espontáneas.
El uso de las voces limpio y poco con la acepción de abundancia o de cantidades profusas, son propias, principalmente, de la región sur andina de Nariño $y$, en su realización, presentan connotaciones particulares que revierten en la autenticidad e identidad del hablante. Es propio decir que el pensamiento andino, fusionado con algunas particularidades del pensamiento occidental, adquiere características originales e incomprensibles para el hablante inadvertido.

\section{Referencias}

Álvarez, J. (1984). El castellano en Nariño. Pasto: Biblioteca Nariñense de Bolsillo.

Arbor, H. (1975). Apuntes lexicográficos del español hablado en Nariño. Thesaurus, Boletín del Instituto Caro y Cuervo, 30 (23).

Bolaños, H. (1975). Diccionario pastuso. Pasto: Imprenta del Departamento.

Cisneros, M. (2001). Peculiaridades del gerundio en el suroccidente de Colombia. Thesavrvs, 54 (3), 1003-1035.

Hymes, D. (1971). Acerca de la competencia comunicativa. En M. Llobera (coord.) (1995). Competencia comunicativa: documentos básicos en la enseñanza de lenguas extranjeras (pp. 27-46). Madrid: Edelsa.

Hymes, D. (1976). La sociolingüística y la etnografía del habla. En E. Ardener (ed.) Antropología social y lenguaje (pp. 115-151). Buenos Aires: Paidós.

Maffla, A. (2006). Voces del folclor de la zona andina nariñense. En Manual de Historia de Pasto (tomo 8). Pasto: Academia Nariñense de Historia.

Maffla, A., Ramírez, R., y Bastidas, J. (2012). Observaciones sobre el habla de la zona andina nariñense. En varios autores, Lenguaje en Colombia (pp. 95-108). Bogotá: Imprenta Patriótica del Instituto Caro y Cuervo.

Moliner, M. (1998). Diccionario de uso del español. Madrid: Editorial Gredos.

Pabón, R. (1988). Consideraciones sobre la evolución del dialecto nariñense serrano. En Pasto 450 años de historia y cultura, Pasto: IADAP.

Pazos, A. (1972). El habla popular en Nariño. Cultura Nariñense, 43.

Ramírez, R. (1996). Dimensión sociolingüística de las formas de tratamiento ritual en Nariño. Revista Criterios, 3 (1). 
Ramírez, R. (1994). Algunas observaciones sobre la fonética y la fonología de las formas de tratamiento ritual en Nariño. Revista Criterios, 1(2).

Real Academia Española (2003). Diccionario de la lengua española (vigésima segunda edición). Madrid: Espasa.

Real Academia Española (1992). Diccionario ilustrado Vox latino-español/español-latino (decimonovena edición). Barcelona: Bibliograf.

Sanz, R. (2006). Diccionario de la lengua pastusa. Pasto: Alcaldía Municipal de Pasto.
Tezanos, A. (2000). Una etnografía de la etnografía. Bogotá: Anthropos.

Tandioy, D., Levinson, S., Maffla, A. (1978). Diccionario inga del Valle de Sibundoy. Intendencia del Putumayo: Townsend.

Wittgenstein, L. (1958/1988). Investigaciones filosóficas. Barcelona: Crítica.

Wittgenstein, L. (1969/2000). Sobre la certeza. Barcelona: Gedisa. 